\title{
Developing microalgal oil production for an outdoor photobioreactor
}

\author{
Niels-Henrik Norsker ${ }^{1,2}$ (D) Maria Cuaresma ${ }^{1,3}$ (D) Pauliina Uronen ${ }^{4} \cdot$ Maria J. Barbosa $^{1} \cdot$ René Wijffels $^{1,5}$ (D)
}

Received: 4 August 2020 / Revised and accepted: 3 January 2021 / Published online: 12 March 2021

(C) The Author(s) 2021

\begin{abstract}
In this paper the preparations are described to develop a production of oil rich microalgal biomass under south European conditions. Ten microalgal species were compared in shake flasks in an incubator for potential for oil production. Potential oil production capacity was assayed as maximum total fatty acid (TFA) concentration and volumetric TFA productivity. TFA concentration ranged from 5 to $40 \%$ DW while TFA productivity rate ranged from 0 to $204 \mathrm{mg} \mathrm{TFA} \mathrm{L}^{-1}$ day $^{-1}$. To control the oil enrichment process in the outdoor microalgal batch culture, a quadratic equation was proposed, predicting the TFA concentration based on biomass inverse nitrogen quota. A concentrated substrate was developed to add to sea water, made from natural sea-salt and tap water.
\end{abstract}

Keywords Oil $\cdot$ Fatty acids $\cdot$ Algal production $\cdot$ Strains $\cdot$ Oil enhancement

\section{Introduction}

Industrial scale photosynthetic production of microalgal biomass mainly depends on open-pond technology whereas photobioreactor technology is applied to produce high-value products and inoculum for pond production. This paper reports on the achievements to develop microalgal oil production for fuel, based on a disposable, soft-sleve tubular photobioreactor. The tubes were placed on the ground, which was partly to avoid the high cost of scaffolding, partly out of necessity as the soft sleeves require full-length support from below. A tube diameter of $6 \mathrm{~cm}$ was selected in accordance with Acién Fernández et al. (2001). Length of the tubes was $32 \mathrm{~m}$, i.e., the culture would run of $64 \mathrm{~m}$ before returning for degassing.

The current work was carried out in 2010 and 2011, and the purpose was to select a suitable strain to test the tubular microalgal biomass production technology, which was

Niels-Henrik Norsker

nhnorsker@biotopic.dk

Wageningen University, Wageningen, The Netherlands

2 Biotopic, Vester Skerninge, Denmark

Universidad de Huelva, Huelva, Spain

4 Neste Corporation, Espoo, Finland

5 Nord University, Bodø, Norway proposed in Norsker et al. (2011) and to develop methodology to enhance the microalgal oil productivity. The study was a technical-economic analysis of various algal production technologies at a Dutch location at 100 ha scale. The technologies compared were open ponds, soft-sleve tubular photobioreactors and vertical, $1 \mathrm{~m}$ tall, flat panels, spaced with $1 \mathrm{~m}$ distance. Out of these 3 technologies, the biomass production costs for the tubular plant were projected as the lowest $\left(€ 4.15 \mathrm{~kg}^{-1} \mathrm{DW}\right)$. South-west Spain was selected as experimental site because of low annual cloudiness which results in monthly average daily irradiance in the 4 winter months being around $10 \mathrm{MJ} \mathrm{m}^{-2}$ day $^{-1}$ and during the rest of the year 20 $25 \mathrm{MJ} \mathrm{m}^{-2}$ day $^{-1}$ with some days peaking around $30 \mathrm{MJ} \mathrm{m}^{-2}$ day $^{-1}$ whereas summer temperatures rarely exceed $35^{\circ}$. Relatively cool summers, combined with high, sustained irradiance are good conditions to establish microalgal oil production.

Huelva University provided access to both laboratory and processing facilities and suitable outdoor space for the later pilot reactor tests at its field research station in Matalascañas. For a soft sleeve tubing photobioreactor, a plane and relatively smooth surface is necessary, and this was provided around the buildings. Batch production technique was applied because it is more simple to use with nutrient limitation than continuous production. Batch production in practice requires a sustained supply of starter culture for the reactor but the short production cycles also means lower sanitary demands as predatory or competing organisms are normally not allowed sufficient time to attain troublesome concentrations in the plant. 
Oil quantification is a problem area in microalgal oil production because of the requirement for rapid feedback on the stage of the product formation. The oil content may be quantified as total lipid, TFA (total fatty acid), or TAG (triacyl glycerol). TAG only includes fatty acids that are esterified with glycerol but not fatty acids in phospholipids and glycolipids that may constitute a significant part of the fatty acids in algae, particularly under nutrient repletion. The lipid fraction contains in addition to fatty acids also chlorophyll, carbohydrate moieties of glycolipids, and other non-oil pigments. Discrepancy between lipid and TFA content may be considerable. The cleaned lipid fraction (fatty acid), for example, in the work of Choi et al., constituted $74 \%$ of the crude extract from Scenedesmus obliquus (Choi et al. 1987).

Analysis of microalgal oil content normally is done following Soxhlet, Bligh \& Dyer, or Folch extraction methods. These are multistep time-consuming methods, often involving large quantities of solvents. (Ahmad et al. 2018). Direct transesterification methods that skip the initial lipid extraction step are faster (Cavonius et al. 2014), but still follow lengthy laboratory protocols. Accelerated solvent extraction, using high pressure extraction cycles, is a faster, automated process which is useful for high throughput analytical purposes.

Mass spectroscopy (CHNO analysis) may serve to predict fatty acid content but not normally available at microalgal production plants. A relation between total microalgal fatty acid content and C:N ratio was indeed found in the current study.

Staining lipid bodies in intact cells with fluorescent probes BODIPY and Nile red is being developed in combination with flow cytometry for quantitative analysis of microalgal neutral lipids. Long time required for reaction and detection, permeability differences between in different algal strains, and cost of the probes have so-far limited the practical use of the method (Giordano and Wang, 2018, Cointet et al. 2019). Nuclear magnetic resonance technology was used by Bono et al. (2015) to calibrate the flow cytometry fluorescence signals and could thus not only provide quantitative neutral lipid measurement but also cell distribution information.

Fourier transformed infrared analysis or Raman spectroscopy are other possible candidates for quantitative lipid analysis in microalgae.

Proxy assays may be of help in developing microalgal oil production. Non-destructive carotenoid-chlorophyll ratio, measured on a spectrophotometer, was used as an in-direct measure of TFA content in Nannochloropsis oceanica (Solovchenko et al. 2010).

In the current work, we developed another proxy assay, the inverse nitrogen quota method to predict and control microalgal fatty acid content.

\section{Strains for oil production}

The selection of production strain is one of the most critical steps in microalgal oil production development.
Oil production has been investigated with a number of strains under laboratory conditions, including Chlorella vulgaris, Chlorella zofingiensis, Nannochloris sp., Scenedesmus obliquus, Dunaliella tertiolecta, Isochrysis galbana, Phaeodactylum tricornutum, Porphyridium cruentum, Chlorococcum littorale, Nannochloropsis oculata, Nannochloropsis sp., Neochloris oleoabundans, Stichococcus bacillaris and Tetraselmis suecica.

These strains were illuminated continuously at 150 $190 \mu \mathrm{mol}$ photons $\mathrm{m}^{-2} \mathrm{~s}^{-1}$ in shake flasks and analyzed in terms of fatty acid content and volumetric productivity.

The highest fatty acid productivities were exhibited by nitrogen deplete Scenedesmus $\left(360 \mathrm{mg} \mathrm{L}^{-1} \mathrm{day}^{-1}\right)$ and Nannochloropsis sp. (238 mg L ${ }^{-1}$ day $^{-1}$ ) (Breuer et al. 2012, Benvenuti et al. 2015). Oil rich subpopulations of $C$. littorale were selected with cell sorting and TAG productivity was increased from originally 180 to $340 \mathrm{mg} \mathrm{L}^{-1}$ day $^{-1}$ in flat panel reactors under $400 \mu \mathrm{mol}$ photons $\mathrm{m}^{-2} \mathrm{~s}^{-1}$ irradiance (Cabanelas et al. 2016). TAG content will be less than the TFA content but approaches the TFA content under nitrogen limitation.

In Italy, Rodolfi et al. (2009) maintained a lipid productivity with Nannochloropsis sp. in a green wall panel of $204 \mathrm{mg} \mathrm{L}^{-1}$ day $^{-1}$ as a daily average over the first 3 days at a daily average irradiance of $15 \mathrm{MJ} \mathrm{m}^{-2}$ day $^{-1}$. Accumulated irradiance corresponded to a continuous PAR of $343 \mu \mathrm{mol}$ photons $\mathrm{m}^{-2} \mathrm{~s}^{-1}$. In Germany, Münkel et al. (2013) obtained an average volumetric TFA productivity with $C$. vulgaris under N- and P-deprivation of $390 \mathrm{mg} \mathrm{TFA} \mathrm{L}^{-1}$ day $^{-1}$ at a TFA concentration of $44.8 \% \mathrm{DW}$ in an outdoor, vertical flat panel reactor during summer (average global irradiance in the period: $15.9 \mathrm{MJ} \mathrm{m}^{-2}$, corresponding to $340 \mu \mathrm{mol}$ photons $\mathrm{m}^{-2} \mathrm{~s}^{-1}$ continuous PAR irradiance).

In terms of volumetric TFA productivity, there is little difference between current best practices: current best laboratory results are $340 \mathrm{mg} \mathrm{TFA} \mathrm{L}^{-1}$ day $^{-1}$ and best outdoor results are $390 \mathrm{mg} \mathrm{L}^{-1}$ day $^{-1}$.

\section{Oil production enhancement}

The production of microalgal oils generally follows a twophase pattern with the main biomass production taking place in a nutrient replete stage while enhancement of oil content may follow in a nutrient depleted phase, during which biomass production is reduced or even may become negative. Nitrogen limited, continuous fatty acid production technology has also been proposed but appears not as efficient as batch technology in terms of volumetric productivity (Klok et al. 2013, Remmers et al. 2017). With continuous production of $N$. oleoabundans, $79 \mathrm{mg} \mathrm{TFA} \mathrm{L}{ }^{-1}$ day $^{-1}$ was produced under nitrogen limitation whereas nitrogen sufficient productivity was $118 \mathrm{mg}$ (Klok et al. 2013). Continuous production of nitrogen limited Acutodesmus obliquus resulted in a TAG 
productivity of $0.11 \mathrm{~g} \mathrm{~L}^{-1}$ day $^{-1}$ while batch productivity resulted in $0.23 \mathrm{~g} \mathrm{TAG} \mathrm{L}^{-1}$ day $^{-1}$ (Remmers et al. 2017).

Until the discovery of Nannochloropsis strains that could maintain significant biomass growth for an extended period of time after nitrogen depletion (Rodolfi et al. 2009), nutrient depletion normally resulted in higher fatty acid concentrations but lower productivity than nutrient replete cultures. Breuer et al. (2012) found that the main difference in TAG productivity between the strains examined was explained by biomass productivity and capability to sustain biomass production after onset of nitrogen limitation.

It is important to notice that nutrient depletion is not necessarily advantageous in terms of lipid productivity; whereas nutrient deplete Nannochloropsis may produce the highest lipid yields, the efforts associated with a limitation phase in large scale should also be considered. On the other hand, certain extraction protocols require high TAG contents. Fatty acid content and productivity potential, with and without nutrient limitation, is therefore important for the evaluation of feasibility of a given strain.

\section{Current research objectives}

For the strains selection fatty acid productivity and fatty acid content in biomass was tested under nitrogen deplete and replete conditions in 10 selected strains. Strains C. littorale, N. oleoabundans, Nannochloropsis sp., P. tricornutum, Acutodesmus (Scenedesmus) obliquus, and Botryococcus braunii were selected as being among the most frequently investigated strains in microalgal oil studies, whereas P. cruentum, T. suecica, and Chlorella sorokiniana are known as prolific biomass producers in large-scale. Scenedesmus sp. (M) was a local Spanish isolate that had shown promise in previous outdoor cultivation trials.

A short-term, shake flask assay was devised for an orbital shake-flask incubator with start volumes of $100 \mathrm{~mL}$, which was sufficient for 2 biomass and fatty acid samples.

To implement nitrogen limitation in outdoor batch cultures where the nitrogen limitation state of the culture can be difficult to assess and is influenced by the actual weather conditions, we aimed to develop a method to control the nitrogen supply of the culture, the inverse nitrogen quota as a means to predict or control the fatty acid content of the culture. The procedure involves establishing the relation (formula) between the inverse nitrogen quota and the associated fatty acid content in a laboratory assay.

In the outdoor production, the inverse nitrogen quota is calculated as the biomass concentration of the culture, divided by the total assimilated nitrogen of the culture. The algal fatty acid content can then be estimated from the laboratory formula. The formula is species-specific.

With a batch cultivation and oil enrichment protocol, a steady supply of starter culture must be provided for the photobioreactor. To estimate the minimum inoculation biomass concentration, we measured the maximum sustainable light exposure of the selected strain in the laboratory from fluorometric quantum yield. From the average light intensity inside the outdoor tubular photobioreactor, a minimum inoculation biomass density was then estimated.

Growth medium for the outdoor algal production may be made from natural or artificial seasalt mix, dissolved in tap water. To supply nutrients, a nutrient solution was developed that could be made in concentrated form and kept for extended periods of time without precipitation.

Finally, the minimum biomass concentration for inoculation of an out-door photobioreactor was investigated. With smaller photobioreactors, initial covering of the reactor may be practiced to avoid photoinhibition but large reactors must be started with a sufficient biomass concentration to avoid photoinhibition.

\section{Materials and methods}

\section{Analyses}

Fatty acids were measured in a modified Bligh \& Dyer analysis (Breuer et al. 2013).

Total fatty acid productivity, $P t f a_{n}$ from day 0 to day $n$ was calculated according to:

$P t f a_{n}=\left(\left(C b_{n} * X t f a_{n}\right)-\left(C b_{0} * X t f a_{0}\right)\right) / n \quad\left[\mathrm{~kg} \mathrm{~m}^{-3} \mathrm{day}^{-1}\right]$

with $C b_{n}$ being biomass concentration in biomass on day $n[\mathrm{~kg}$ $\left.\mathrm{dw} \mathrm{m}{ }^{-1}\right], C b_{0}$ being biomass concentration in the reactor at the first day of lipid sampling $\left[\mathrm{kg} \mathrm{dw} \mathrm{m}^{-1}\right], X t f a_{n}$ being total fatty acid fraction of biomass at day $n$ [dimensionless], and Xtfa being total fatty acid fraction of biomass at the first day of sampling and $n$ the day number after the beginning of the lipid sampling [dimensionless].

Biomass dry weight was measured in triplicate on pre-dried GF/F glassfiber filters, washing the filters with $0.5 \mathrm{M}$ ammonium formate before drying for $24 \mathrm{~h}$ at $95^{\circ} \mathrm{C}$.

Residual medium nitrate was measured spectrophotometrically after reduction to nitrite with a cadmium-based Hach Lange kit:

Kit 8039, High Range (0.3-30 mg L $\left.{ }^{-1} \mathrm{NO}_{3}-\mathrm{N}\right)$

Kit 8171, Medium Range (0.1-10 $\left.\mathrm{mg} \mathrm{L}^{-1} \mathrm{NO}_{3}-\mathrm{N}\right)$

Kit 8192, Low Range (0.01-0.5 mg L $\left.{ }^{-1} \mathrm{NO}_{3}-\mathrm{N}\right)$.

Spectrophotometer used with the kits: DR5000 spectrophotometer Hach Lange, Germany.

Optical density was measured at 735,680 , and $530 \mathrm{~nm}$ on a Genesys UV-10, Thermo Spectronic or, in other situations, on a Bausch \& Lomb Spectronic 20 spectrophotometer. The ratio 
$\mathrm{OD}_{680} / \mathrm{OD}_{530}$ was taken as an indicator of chlorophyll content in microalgal biomass (Bosma et al. 2008).

Absorption coefficient was measured in a 6 -cm cuvette spectrophotometer equipped with an integrating sphere.

Absorption coefficient $K_{a}$, was calculated according to:

$$
K_{a}\left[m^{2} * k g^{-1}\right]=A_{400-700 n m} * F * \ln (10) * L^{-1} * C b^{-1}
$$

with $\mathrm{L}=$ cuvette light path $[\mathrm{m}] ; C b=\left[\mathrm{kg} \mathrm{m}^{-3}\right]$, and $\mathrm{F}=$ dilution factor for cuvette.

Irradiance was measured with a Licor Li-250 A meter with a $2 \pi$ PAR sensor. In the shake-flask incubator, the sensor was placed at different points between the flasks and directed towards the light source. Irradiance varied between 150 and $205 \mu \mathrm{mol}$ photons $\mathrm{m}^{-2} \mathrm{~s}^{-1}$ with an average close to $200 \mu \mathrm{mol}$ photons $\mathrm{m}^{-2} \mathrm{~s}^{-1}$. Position of the flasks in the incubator were shifted on a daily base to ensure equal irradiance. For the flat panel photobioreactors, used with the inverse nitrogen ratio measurements, light intensity was measured at the surface of the water filled aquarium that the reactors were placed in.

Outdoor irradiance data were kindly provided by the meteorological station at INTA (Instituto Nacional de Técnicas Aeroespaciales), belonging to the Spanish Ministry of Defense, situated at Arenosillo, about $25 \mathrm{~km}$ from the experimental research station in Matalascañas. Data used were hourly global irradiance (in $\mathrm{kJ} \mathrm{m}^{-2}$ ).

Hourly values of $\mathrm{kJ} \mathrm{m}^{-2}$ were converted to average PAR quanta ( $\mu \mathrm{mol}$ photons $\mathrm{m}^{-2} \mathrm{~s}^{-1}$ ) multiplying with the factor: $10^{3} / 3600 * 4.6 * 0.43$ (Slegers et al. 2011).

\section{Strains selection assay}

To select suitable fatty acid producing species, 10 strains were tested in duplicate for fatty acid yield and fatty acid productivity in a $250-\mathrm{mL}$ conical flasks assay (Table 1 ). The algal strains were incubated in Bold's Basal medium (Pruvost et al. 2009) or Zou medium (Zou and Richmond, 1999), [ $\left[\mathrm{NO}_{3}\right]$ in both media set to 5 or $15 \mathrm{mM}$.

Both media were added $1 \mathrm{~mL}$ vitamin solution (composition per liter: B1, 1.2 g; B12, 75 mg; Biotin, 375 mg).

The flasks were inoculated at relatively high biomass concentrations $\left(\mathrm{OD}_{530}=0.2\right)$ and incubated in an orbital shake incubator at continuous irradiance of $200 \mu \mathrm{mol}$ photons $\mathrm{m}^{-2} \mathrm{~s}^{-1}$ at $25^{\circ}$ and with $5 \% \mathrm{CO}_{2}$ atmosphere maintained in the incubator. In order to assure an even irradiance, the position of the flasks in the incubator were interchanged daily.

\section{Growth medium}

A concentrated and storage-stable nutrient solution (Table 2) was designed for addition to natural sea water in order to make cultivation medium for high biomass density cultures of marine algae at large scale.

The use of the nutrient solution with natural seawater allowed sodium, calcium, and magnesium to be excluded from the recipe, which resulted in a long-term stable (nonprecipitating) nutrient solution. Twenty milliliter of nutrient solution per liter of final medium was tested with a batch culture of $N$. oleoabundans and sufficed for a biomass concentration of $7 \mathrm{~g} \mathrm{DW} \mathrm{L}^{-1}$.

In the large-scale algal production, biomass concentration was kept below $3 \mathrm{~g} \mathrm{DW} \mathrm{L}^{-1}$.

We designed the medium with a high $\mathrm{N}: \mathrm{P}$ ratio (30) in order to enable high biomass concentrations when growing $P$. tricornutum which requires a N:P ratio ranging from 24 to 45 , depending on growth rate, ranging from to 0 to 0.8 day $^{-1}$ (Terry et al. 1985).

The elemental composition ratio of the medium to that of average phytoplankton (Ho et al. 2003) is given in Table 3. The ratios were normalized with respect to phosphorous.

Elements with strong deviation from natural phytoplankton content included Molybdenum (Mo) (19.61 times higher), Fe (8.47 times higher), and $\mathrm{Cu} 0.15$ times. Mo was increased to avoid interference in nitrogen assimilation from Mo limitation as $\mathrm{Mo}$ is a cofactor in nitrate reductase and limitation can interfere in carbon partitioning under nitrate depletion (Guerra et al. 2013). Fe was increased to avoid iron limitation due to oxidation and precipitation and $\mathrm{Cu}$ was reduced due to low Cu-tolerance in P. tricornutum.

For introduction of nitrogen limitation in the cultivation, the $\mathrm{NaNO}_{3}$ was reduced without modifying the other medium components.

\section{Inverse nitrogen quota}

Four flat panel photobioreactors (cuvettes from Photon Systems FMT 150) with a light-path of $2 \mathrm{~cm}$ and a working volume of $400 \mathrm{~mL}$ were used. The photobioreactor units were placed in pairs in two aquaria and operated in batch mode.

Mixing of the cultures was done by aeration. A mixture of air and carbon dioxide was supplied to the culture broth through a metal tube with holes placed at the bottom. Before entering the system, the flow rate of both gases was set with two independent mass flow controllers to obtain a final $\mathrm{CO}_{2}$ concentration of $2 \% \mathrm{v} / \mathrm{v}$. The gas was humidified to minimize evaporation inside the reactors. The total gas flow rate was $1.12 \mathrm{~L} \mathrm{~min}^{-1}$ and it was distributed equally between the four photobioreactor units.

Temperature was controlled at $25^{\circ} \mathrm{C}$ with a water bath with an external recirculation loop, connected to the aquaria. The 4 photobioreactor units were placed in the aquaria which were connected to the recirculation loop. An external temperature sensor connected to the water bath was placed in one of the aquaria to maintain the temperature according to the setpoint. 
Table 1 List of strains included in the strain's selection

\begin{tabular}{lll}
\hline Strain & Designation & Medium \\
\hline Tetraselmis suecica & UTEX LB2286 & Zou (modified) \\
Nannochloropsis sp. & CCAP 211/78 & Zou (modified) \\
Phaeodactylum tricornutum & UTEX 640 & Zou (modified) \\
Porphyridium cruentum & UTEX 161 & Zou (modified) \\
Chlorococcum littorale & NBRC 102761 & Zou (modified) \\
Botryococcus braunii & UTEX 572 & BBM (modified) \\
Neochloris oleoabundans & UTEX 1185 & BBM (modified) \\
Scenedesmus obliquus & SAG 276-3a & BBM (modified) \\
Chlorella sorokiniana & Not known & BBM (modified) \\
Scenedesmus sp. (local, Matalascañas) & Own isolate & BBM (modified) \\
\hline
\end{tabular}

Each aquarium contained 2 photobioreactor units with the two different initial nitrogen concentrations $(10 \mathrm{mM}$ and $2.5 \mathrm{mM}$ of nitrate).

Two panels with fluorescent lamps were used to provide continuous illumination of the photobioreactors at an incident intensity of $120 \mu \mathrm{mol}$ photons $\mathrm{m}^{-2} \mathrm{~s}^{-1}$.

Light input, temperature, and air and $\mathrm{CO}_{2}$ flow were set at the beginning of the cultivation and the flow of $\mathrm{CO}_{2}$ was adjusted to set $\mathrm{pH}$ around 7 .

The cultures were followed for 15 days $(2.5 \mathrm{mM}$ nitrate cultures) and 22 days (10 mM nitrate cultures). The $2.5 \mathrm{mM}$ nitrate-cultures were running out of residual nitrate after about 4 days and the $10 \mathrm{mM}$ nitrate-cultures after about 15 days.
Residual nitrate was followed in the medium at several points throughout the test, in a photometric assay with two different reaction kits with a dynamic range of $0.3-30 \mathrm{mg}$ $\mathrm{NO}_{3}-\mathrm{N} \mathrm{L}^{-1}$ and $0.01-0.5 \mathrm{mg} \mathrm{NO}_{3}-\mathrm{N} \mathrm{L}^{-1}$, respectively.

$\mathrm{pH}$ control was done indirectly via carbon dioxide addition. The fixed $\mathrm{CO}_{2}$ concentration supplied to the systems resulted in a stable $\mathrm{pH}$ in the cultures. The inverse nitrogen quota was calculated according to Eq. 3 .

$\boldsymbol{r}_{N}^{-1}(\boldsymbol{t})=\frac{\boldsymbol{C}_{\boldsymbol{b}}(\boldsymbol{t})}{\left(\boldsymbol{N}_{\mathbf{0}}-\boldsymbol{N}_{\boldsymbol{t}}\right)}\left[\mathrm{g} \mathrm{mmol}^{-1}\right]$

with $C_{b}(t)\left[g D W L^{-1}\right]$ denoting culture biomass concentration at time $t$, and $N_{O}$ and $N_{t}[\mathrm{mM}]$ denoting culture initial and
Table 2 Composition of the medium, used to propagate and produce the microalgal species in the study

\begin{tabular}{|c|c|c|}
\hline Trace mineral stock & Resulting concentration in medium & Per liter stock solution \\
\hline $\mathrm{Na}_{2}$ EDTA & $282 \mu \mathrm{M}$ & $45 \mathrm{~g}$ \\
\hline $\mathrm{FeSO}_{4} \cdot 7 \mathrm{H}_{2} \mathrm{O}$ & $108 \mu \mathrm{M}$ & $30 \mathrm{~g}$ \\
\hline $\mathrm{MnCl}_{2} \cdot 2 \mathrm{H}_{2} \mathrm{O}$ & $11 \mu \mathrm{M}$ & $1.71 \mathrm{~g}$ \\
\hline $\mathrm{ZnSO}_{4} \cdot 7 \mathrm{H}_{2} \mathrm{O}$ & $2.3 \mu \mathrm{M}$ & $0.66 \mathrm{~g}$ \\
\hline $\mathrm{Co}\left(\mathrm{NO}_{3}\right)_{2} \cdot 6 \mathrm{H}_{2} \mathrm{O}$ & $0.24 \mu \mathrm{M}$ & $70 \mathrm{mg}$ \\
\hline $\mathrm{CuSO}_{4} \cdot 5 \mathrm{H}_{2} \mathrm{O}$ & $0.1 \mu \mathrm{M}$ & $24 \mathrm{mg}$ \\
\hline $\mathrm{Na}_{2} \mathrm{MoO}_{4} \cdot 2 \mathrm{H}_{2} \mathrm{O}$ & $1.1 \mu \mathrm{M}$ & $242 \mathrm{mg}$ \\
\hline \multicolumn{3}{|l|}{$\mathrm{pH}$ adjusted to about 4} \\
\hline Deionised water & ad tot vol. $1 \mathrm{~L}$ & \\
\hline Nutrient solution & Resulting concentration in medium & Per liter nutrient solution \\
\hline $\mathrm{NaNO}_{3}$ & $50 \mathrm{mM}$ & $212 \mathrm{~g}$ \\
\hline $\mathrm{KH}_{2} \mathrm{PO}_{4}$ & $1.7 \mathrm{mM}$ & $11.5 \mathrm{~g}$ \\
\hline $\mathrm{Na}_{2}$ EDTA & $173 \mu \mathrm{M}$ & 3 \\
\hline Trace mineral stock & & $50 \mathrm{~mL}$ \\
\hline \multicolumn{3}{|l|}{$\mathrm{pH}$ adjusted to $7.5-7.6$} \\
\hline Deion. water & ad tot vol. $1 \mathrm{~L}$ & \\
\hline \multicolumn{3}{|l|}{ Medium } \\
\hline Nutrient solution & $20 \mathrm{~mL}$ & \\
\hline Natural seawater & ad tot vol. $1 \mathrm{~L}$ & \\
\hline
\end{tabular}


Table 3 P-normalized elemental ratios in the medium, relative to equivalent cell quotas for average phytoplankton in (Ho et al. 2003)

\begin{tabular}{ll}
\hline Element & Ratio \\
\hline $\mathrm{P}$ & 1.00 \\
$\mathrm{~N}$ & 1.84 \\
$\mathrm{Fe}$ & 8.47 \\
$\mathrm{Mn}$ & 1.70 \\
$\mathrm{Zn}$ & 3.55 \\
$\mathrm{Co}$ & 0.74 \\
$\mathrm{Cu}$ & 0.15 \\
$\mathrm{Mo}$ & 19.61 \\
\hline
\end{tabular}

residual nitrogen concentration, respectively. Nitrogen added with the inoculum is also included in $N_{0}$.

\section{Mass spectroscopy}

Elemental analysis of dried algal biomass samples from the inverse nitrogen quota assay was performed by a Thermo Scientific Flash 2000 carbon-hydrogen-nitrogen elemental analyzer. It measures the mass- $\% \mathrm{C}, \mathrm{H}$ and $\mathrm{N}$ for a sample and $\mathrm{O}$ is determined by difference $(\mathrm{O}=100 \%-\% \mathrm{C}-\% \mathrm{~N}-\% \mathrm{H})$. Duplicates are typically within $\pm 1 \%$.

\section{Average irradiance}

$I_{a v}$, average irradiance in the tubular reactor, was calculated from the integrated Lambert-Beer formula:

$\boldsymbol{I}_{\boldsymbol{a} v}=\frac{\boldsymbol{I}_{\mathbf{0}}}{\boldsymbol{p}^{*} \boldsymbol{C}_{\boldsymbol{b}} * \boldsymbol{K}_{\boldsymbol{a}}}\left(\mathbf{1}-\exp \left(-\boldsymbol{p}^{*} \boldsymbol{C}_{\boldsymbol{b}} * \boldsymbol{K}_{\boldsymbol{a}}\right)\right)\left[\right.$ mol photons $\left.\mathrm{m}^{-2} \mathrm{~s}^{-1}\right]$

Surface irradiance, $I_{0}\left[\mu \mathrm{mol}\right.$ photons $\mathrm{m}^{-2} \mathrm{~s}^{-1}$, was taken as the irradiance on the horizontal projection of the tubes. $P[\mathrm{~m}]$, the photic depth was taken as the tube diameter. $C_{b}\left[\mathrm{~g} \mathrm{~m}^{-3}\right]$ is biomass concentration and $K_{a}\left[\mathrm{~m}^{2} \mathrm{~kg}^{-1}\right]$ is the absorption coefficient for the algal biomass.

The absorption coefficient, $K_{a}$, was determined in a spectrophotometer equipped with an integrating sphere for low light adapted Neochloris.

\section{Results}

\section{Strains selection}

Figure 1 is a comparison of the color of the $5 \mathrm{mM}$ and $15 \mathrm{mM}$ N. oleoabundans-flasks on day 3.71 (a) and on day 4.94 (b). It is evident that the color of the $5 \mathrm{mM} \mathrm{NO}_{3}$ flasks on day 4.94 had started to become pale in comparison with the
$15 \mathrm{mM} \mathrm{NO}_{3}$ flasks. These pigment changes were followed spectrophotometrically in all cultures.

For each strain, two sampling points were determined on the basis of the $\mathrm{OD}_{530}$ value and $\mathrm{OD}_{680} / \mathrm{OD}_{530}$ ratio: $\mathrm{T} 1$, the first point at which the $\mathrm{OD}_{530}$ trend and the $\mathrm{OD}_{680} / \mathrm{OD}_{530}$ trend have started to fall in the $5 \mathrm{mM} \mathrm{NO}_{3}$ flask and nitrogen limitation of could be assumed to have begun and T2, a point before the $\mathrm{OD}_{530}$ trend and $\mathrm{OD}_{680} / \mathrm{OD}_{530}$ trend would be expected to wane in the $15 \mathrm{mM} \mathrm{NO}_{3}$ flasks. In this manner, the $5 \mathrm{mM} \mathrm{NO}_{3}$ cultures could be assumed to exhibit nitrogen deplete fatty acid formation and the $15 \mathrm{mM} \mathrm{NO}_{3}$ a nitrogen replete fatty acid formation rate between $\mathrm{T} 1$ and $\mathrm{T} 2$. As examples of the trends, the trends for $N$. oleoabundans and $C$. littorale are shown in Figs. 2 and 3, respective.

The results of the strains selection are summarized in Fig. 4, where total fatty acid productivity and fatty acid concentration over the period T1-T2 is shown for all 10 strains.

From Fig. 4, it is obvious that N-depleted Nannochloropsis sp. exhibited both the highest total fatty acid formation rate (210 $\mathrm{mg} \mathrm{TFA} \mathrm{L}^{-1}$ day $^{-1}$ ) and total fatty acid content (40\% DW). Phaeodactylum tricornutum showed roughly the same TFA content but lower TFA formation rate $(120 \mathrm{mg}$ TFA $\mathrm{L}^{-1}$ day $^{-1}$ ) in the $\mathrm{N}$-depleted flasks. Neochloris oleoabundans, on the other hand, exhibited approximately the same TFA productivity as Nannochloropsis sp., but lower TFA contents. Chlorococcum littorale exhibited slightly lower TFA productivities than Nannochloropsis sp. but much lower TFA contents.

From laboratory fatty acid production tests, Nannochloropsis sp. resulted as the best strain. Selecting a strain for outdoor fatty acid production, other characteristics may also be considered, such as temperature and light tolerance and amenability for downstream processing. During the strain's selection study, Nannochloropsis sp. was noticed to be sensitive (tended to bleach) at an irradiance above $200 \mu \mathrm{mol}$ photons $\mathrm{m}^{-2} \mathrm{~s}^{-1}$ which could be disadvantageous in outdoor cultivation practice. Phaeodactylum tricornutum was deselected for its low TFA productivity at nitrogen depletion. Consequently, $N$. oleoabundans was selected as the most promising strain for further testing. Chlorococcum littorale also was selected as a reasonably good fatty acid producer both in terms of productivity and contents under nitrogen limitation.

\section{Minimum inoculation biomass density}

To determine the minimum inoculation biomass density, the apparent maximum permissible irradiance was determined in a dilute $\left(\mathrm{C}_{\mathrm{b}}\right.$ about $\left.0.1 \mathrm{~g} \mathrm{DW} \mathrm{L}^{-1}\right)$, continuously irradiated 400-mL flat panel laboratory turbidostat culture. This was done by stepwise raising irradiance and temperature (for 1 day) until the fluorescence-based quantum yield and dilution rate were approaching 0 (Table 4 ). 
Fig. 1 Neochloris oleoabundans flasks photographed a just before the sampling point (T1) and b just after the T1, which marks the beginning of the nitrogen limitation phase in the $5 \mathrm{mM} \mathrm{NO}_{3}$-flasks. Notice that the $15 \mathrm{mM} \mathrm{NO}_{3}$ flasks are considerably darker than the $5 \mathrm{mM} \mathrm{NO}_{3}$ flasks
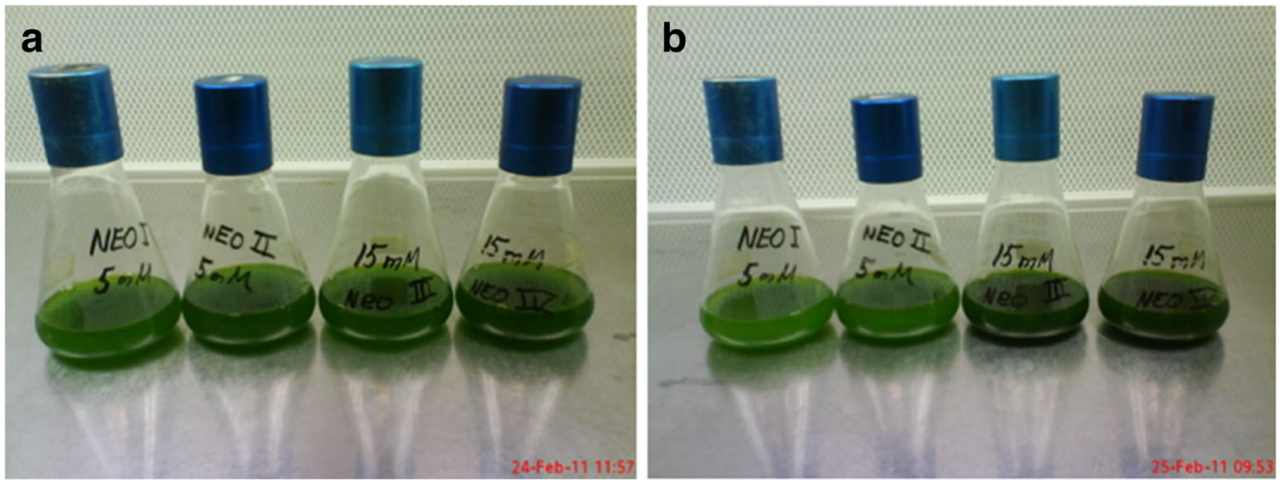

From Table 4, it appears that both dilution rate and quantum yield is strongly reduced at $300 \mu \mathrm{mol}$ photons $\mathrm{m}^{-2} \mathrm{~s}^{-1}$ at $35^{\circ} \mathrm{C}$ compared to the situation at $210 \mu \mathrm{mol}$ photons $\mathrm{m}^{-2} \mathrm{~s}^{-1}$ and it was concluded that the maximum permissible continuous irradiance was $300 \mu \mathrm{mol}$ photons $\mathrm{m}^{-2} \mathrm{~s}^{-1}$ at $35^{\circ} \mathrm{C} .40^{\circ} \mathrm{C}$ was not sustained.

In a high-biomass density outdoor tubular photobioreactor a biomass density was assumed to be safe minimum (i.e., not resulting in photoinhibition) if the average intensity in the tube $\left(\mathrm{I}_{\mathrm{av}}\right)$ did not exceed $300 \mu \mathrm{mol}$ photons $\mathrm{m}^{-2} \mathrm{~s}^{-1}$ for more than $2 \mathrm{~h}$ at noon.

In Fig. $5 I_{a v}$ is depicted against biomass concentration for two irradiance situations: $I_{0}=1277 \mu \mathrm{mol}$ photons $\mathrm{m}^{-2} \mathrm{~s}^{-1}$ which corresponds to the noon irradiance on 06.11.2011 (which is the day with the maximum irradiance in the month of November) and $I_{0}=1221 \mu \mathrm{mol}$ photons $\mathrm{m}^{-2} \mathrm{~s}^{-1}$, which is the irradiance limit only exceeded during the solar hours 11 to 13 (Fig. 6).

Inoculating the $600 \mathrm{~L}$ reactor with a biomass quantity of about $330 \mathrm{~g} \mathrm{~m}^{-3}$ would thus result in an average irradiance exceeding $300 \mu \mathrm{mol}$ photons $\mathrm{m}^{-2} \mathrm{~s}^{-1}$ only during $2 \mathrm{~h}$-which was judged sustainable, and $330 \mathrm{~g}$ DW was therefore considered the minimum permissible biomass for inoculation of the $600 \mathrm{~L}$ reactor.

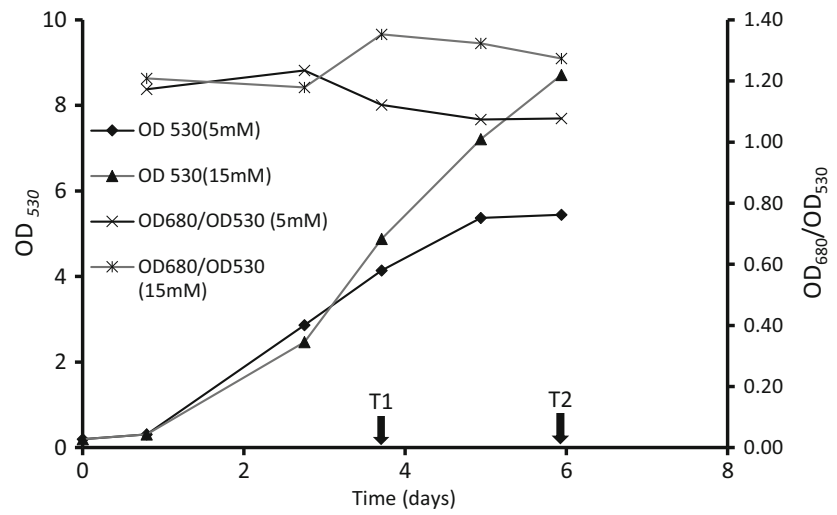

Fig. 2 TFA production in Neochloris oleoabundans. T1 and T2 sample points are indicated with arrows. FA productivity measurement period: $\mathrm{T} 2-\mathrm{T} 1: 5.94-3.71=2.23$ days

\section{Optimization of fatty acid productivity}

For the strains $N$. oleoabundans and $C$. littorale, fatty acid content was depicted against inverse nitrogen ratio in Figs. 7 and 8 and a quadratic polynomium was fitted to the data. For Neochloris the equation is $y=0.4807 x^{2}+0.0893 x+0.1107$ with $y$ being TFA in \% DW and $x$ being inverse nitrogen quota (g DW mmol ${ }^{-1}$ nitrate assimilated). For $C$. littorale, the depiction resulted in $y=0.2071 \mathrm{x}^{2}+0.0818 \mathrm{x}+0.0561$. For C. littorale, the correlation coefficient was 0.93 whereas it was only 0.79 for $N$. oleoabundans.

\section{Discussion}

In the current work techniques were developed to enable a pilot scale test of microalgal oil production.

An easy, practical strain selection method was developed, using 250-mL conical flasks in a shake-flask incubator. Following a spectrophotometry measurement protocol, only 2 samples in 2 replicas were used to determine the fatty acid productivity and fatty acid content in both nitrogen replete and nitrogen deplete cultures and the assay was carried out in a

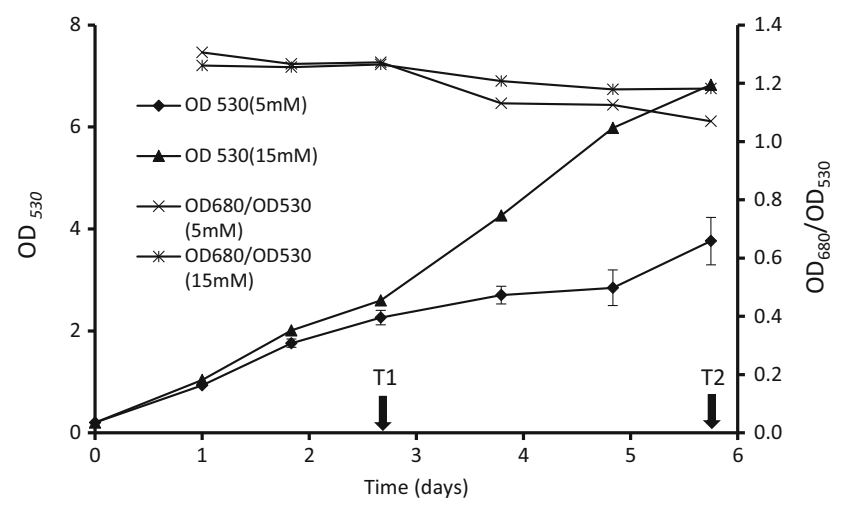

Fig. 3 TFA production in Chlorococcum littorale. T1 and T2 sample points are indicated with arrows. T2 $-\mathrm{T} 1: 5.75-2.67=3.08$ days. It can be noted from the figure that the ratio $\mathrm{OD}{ }_{680} / \mathrm{OD}_{530}$ during the TFA productivity measurement period changes more moderately than with Neochloris oleoabundans 
Fig. 4 Fatty acid productivity (color signature) and fatty acid content (hatched signature) in all 10 strains during short-term from $\mathrm{T} 1$ to $\mathrm{T} 2$. The $5 \mathrm{mM}$ nitrate flasks are assumed to be nitrogen deplete, whereas the $15 \mathrm{mM}$ nitrate flasks are assumed to be nitrogen replete. No values for Botryococcus braunii are shown as the cultures failed to grow during the incubation

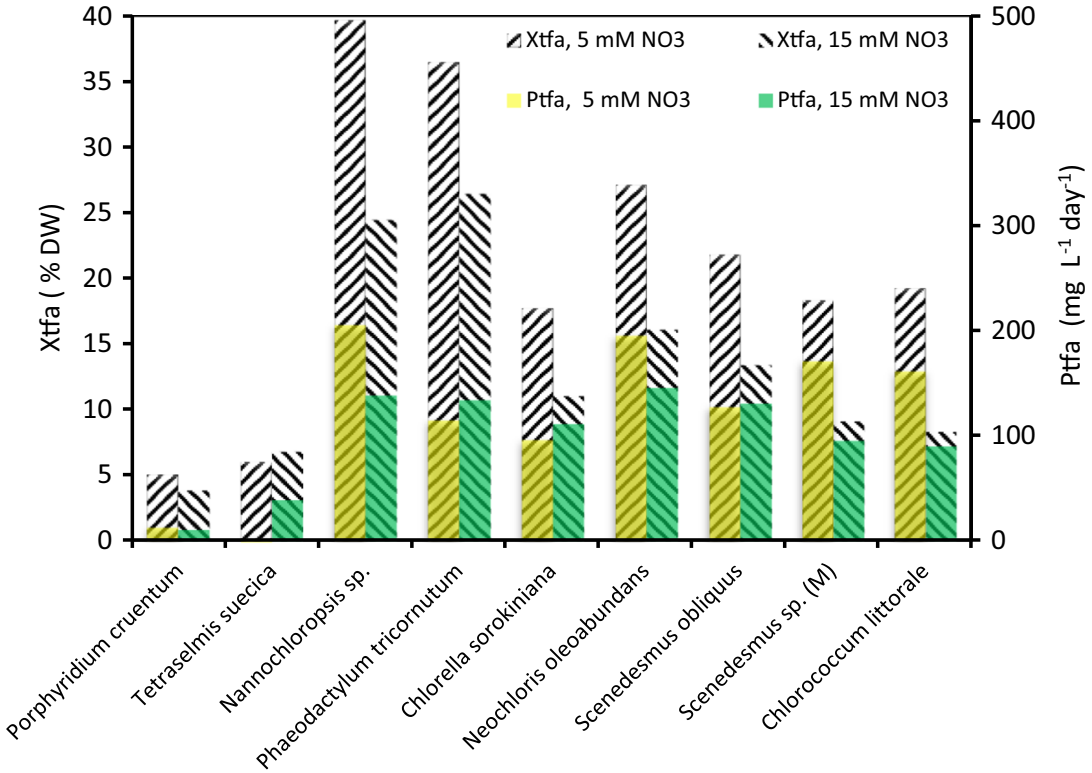

shake flask incubator. The results were comparable to literature values obtained in various laboratory or outdoor photobioreactor experiments. With Nannochloropsis, for example, fatty acid productivity under nitrogen deficiency was $210 \mathrm{mg} \mathrm{TFA} \mathrm{L}^{-1}$ day $^{-1}$ as opposed to $238 \mathrm{mg} \mathrm{TFA} \mathrm{L}^{-1}$ day $^{-1}$ in Benvenuti (2015) or $204 \mathrm{mg}$ TFA L ${ }^{-1}$ day $^{-1}$ in Rodolfi (2009). 161.5 mg TFA L ${ }^{-1}$ day $^{-1}$ was obtained with nitrogen deficient $C$. littorale in the current study as opposed to $180 \mathrm{mg}$ TFA L ${ }^{-1}$ day $^{-1}$ (before cell sorting) in Cabanelas (2016). However, $195.7 \mathrm{mg} \mathrm{TFA} \mathrm{L}^{-1}$ day $^{-1}$ was obtained with nitrogen deplete $N$. oleoabundans in the present study as opposed to $88 \mathrm{mg} \mathrm{TFA} \mathrm{L}^{-1}$ day $^{-1}$ in Benvenuti et al. (2015).

Production of pure starter cultures in sufficient volume is pivotal for successful industrial-scale microalgal production. Starter cultures are propagated in successively larger cultivation volumes, typically diluting the culture at transfer $5-10$ times.

It is difficult to find any rational approach in the literature to determining the minimum safe inoculation biomass density that considers algal species, reactor geometry and solar irradiation. Five to $10 \mathrm{~g} \mathrm{DW} \mathrm{m}^{-2}$ for unspecified strains has been mentioned by Sergejevová et al. (2015). This corresponds to $100-200 \mathrm{~m} \mathrm{~L}^{-1}$ in a single layer tubular photobioreactor with $6 \mathrm{~cm}$ diameter tubes placed closely on the ground.

In a commercial production plant, the production of starter cultures is a major effort and using too high biomass start biomass concentration is economically wasteful whereas using too low biomass concentration may result in loss of the culture. In the current study, a rational approach to deciding the right biomass start concentration level has been proposed. This is useful particularly with planning and developing new productions.

The minimum biomass density found in the current study was $330 \mathrm{~g} \mathrm{dw} \mathrm{m}^{-3}$ for $N$. oleoabundans in $6 \mathrm{~cm}$ diameter, horizontal tubular photobioreactor at a given irradiance conditions.

The approach was based on the assumption that exposure of a microalgal culture to higher irradiation than the continuously maximum sustainable for a period of $2 \mathrm{~h}$ would be safe. Conversely, taking the maximum sustainable irradiance as an absolute maximum for the starter culture would require higher biomass amounts: On a maximum irradiance summer day, it
Table 4 Quantum yield and dilution rate in a Neochloris oleoabundans turbidostat culture at a continuous irradiance of 210 , respective $300 \mu \mathrm{mol}$ photons $\mathrm{m}^{-2} \mathrm{~s}^{-1}$ and temperatures $30-40{ }^{\circ} \mathrm{C}$. The QY is the light adapted fluorescence-based quantum yield as measured by the FMT 150 flat panel photobioreactor from Photic Systems. D is the dilution rate [day ${ }^{-1}$ ]

Irradiance

\begin{tabular}{lll}
\hline Temperature & $210 \mu \mathrm{mol}$ photons $\mathrm{m}^{-2} \mathrm{~s}^{-1}$ & $300 \mu \mathrm{mol} \mathrm{photons} \mathrm{m}^{-2} \mathrm{~s}^{-1}$ \\
$30^{\circ} \mathrm{C}$ & $\mathrm{QY}=0.38, \mathrm{D}=2.6$ & \\
$35^{\circ} \mathrm{C}$ & $\mathrm{QY}=0.35, \mathrm{D}=2.6$ & $\mathrm{QY}=0.24, \mathrm{D}=1.0$ \\
$40^{\circ} \mathrm{C}$ & $\mathrm{QY} \rightarrow 0, \mathrm{D}=0.2$ & \\
\hline
\end{tabular}




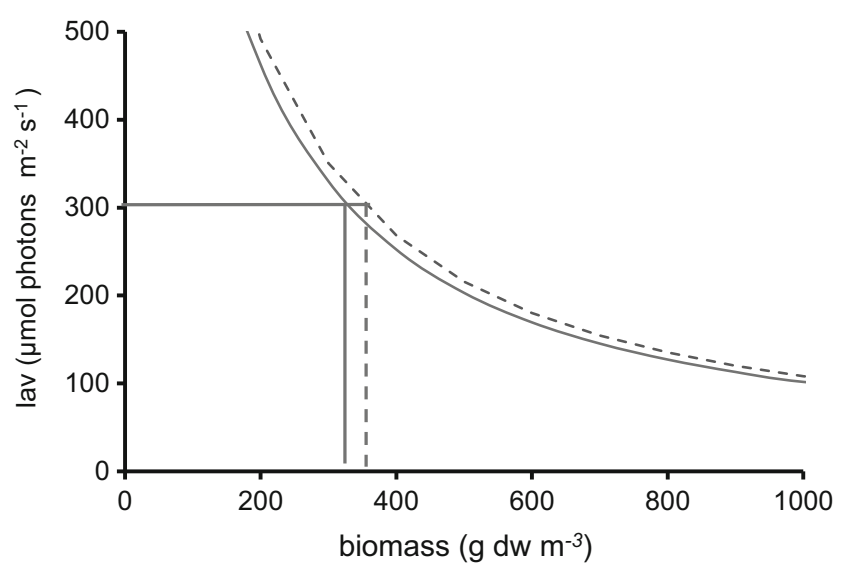

Fig. $5 \mathrm{I}_{\mathrm{av}}$ depicted against biomass density for two situations: $I_{0}=$ $1277 \mu \mathrm{mol}$ photons $\mathrm{m}^{-2} \mathrm{~s}^{-1}$ (dashed line) and $I_{0}=1221 \mu \mathrm{mol}$ photons $\mathrm{m}^{-2} \mathrm{~s}^{-1}$ (full line)

would require a biomass concentration of Neochloris of $550 \mathrm{~g} \mathrm{~m}^{-3}$ to keep the average irradiance in the culture below $300 \mu \mathrm{mol}$ photons $\mathrm{m}^{-2} \mathrm{~s}^{-1}$ at all times. Further fluorimetric analyses and outdoor growth trials would be useful to investigate the concept in depth.

High throughput analysis methods have been proposed to provide necessary product formation feedback with industrial microalgal oil production (Lee et al. 2013, Bono et al. 2015), but these methods are costly in terms of instrumentation and require highly specialized operators and are difficult to envisage as routine tools in industrial microalgal production.

The inverse nitrogen quota method developed in the current work on the other hand may be a useful tool to control the fatty acid enhancement in production scale microalgal cultures. It only requires measurement of biomass concentration and a record of assimilated nitrogen to

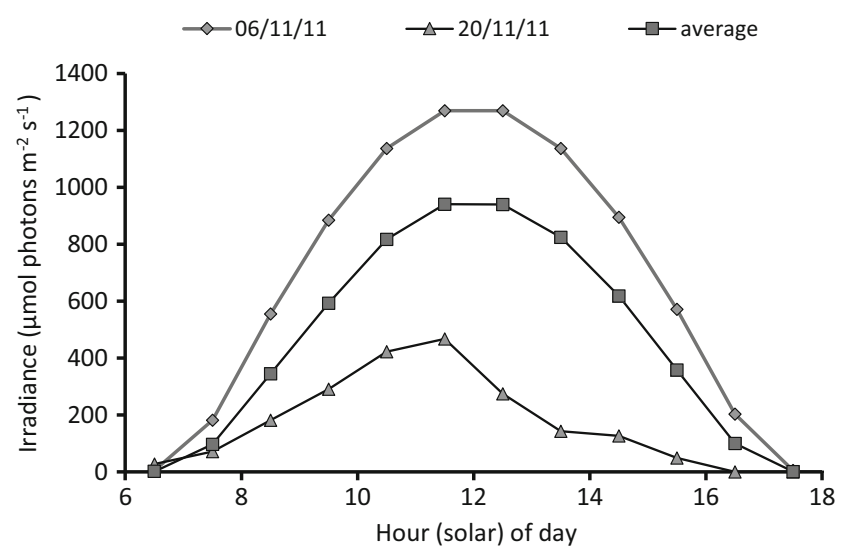

Fig. 6 Hourly average irradiance during November 2011. 06.11.2011 was the day with the highest irradiance whereas the 20.11.2011 was the day with the lowest irradiance. Also depicted is the average irradiance profile of the month

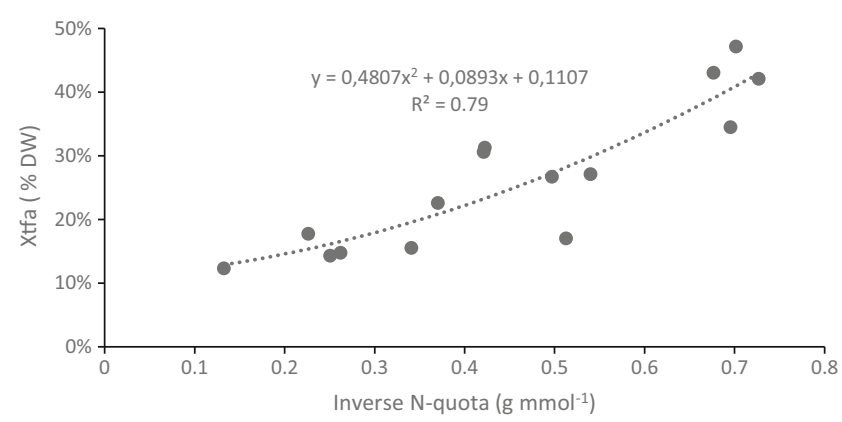

Fig. 7 Total fatty acid content in Neochloris oleoabundans depicted against inverse nitrogen cell quota

predict total fatty acid content in production culture. The correlation between inverse nitrogen quota and TFA content is not very high, particularly for $N$. oleoabundans, $R^{2}=.79$ (Fig. 7) but the variability appeared to be experimental error since analyzing the data from the $2.5 \mathrm{mM} \mathrm{NO}_{3}$ and $10 \mathrm{mM} \mathrm{NO}_{3}$ flasks separately, increased the correlation coefficient to 0.99 and 0.94 , respectively. For $C$. littorale, the overall correlation coefficient was satisfactory (0.93).

The applicability of the method under outdoor environmental conditions needs to be addressed. Concerns could be the effect of nitrogen losses from the culture during growth and the effect of respiratory carbon losses which would be influenced by the time of day that the sample is taken. Ammonia loss which may arise from photorespiration and nitrite excretion is a well-known phenomenon diatom cultures. In this context, it should be kept in mind that the relationship between fatty acid content and inverse nitrogen quota was established under continuous irradiation.

The C:N ratio as measured by elemental analysis of the biomass (C. littorale) was proportional with the fatty acid content (Fig. 9).

Elemental analysis of the biomass could substitute direct fatty acid measurement but this is little useful as a

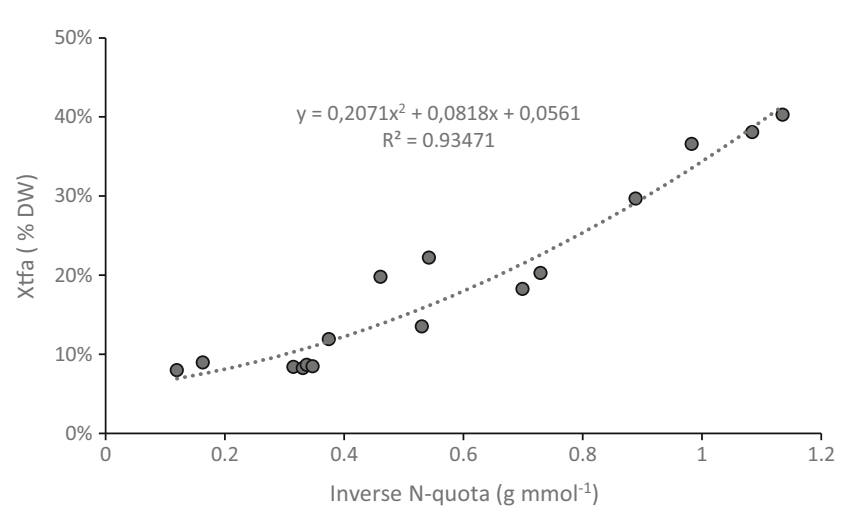

Fig. 8 Total fatty acid content in Chlorococcum littorale depicted against inverse nitrogen cell quota 


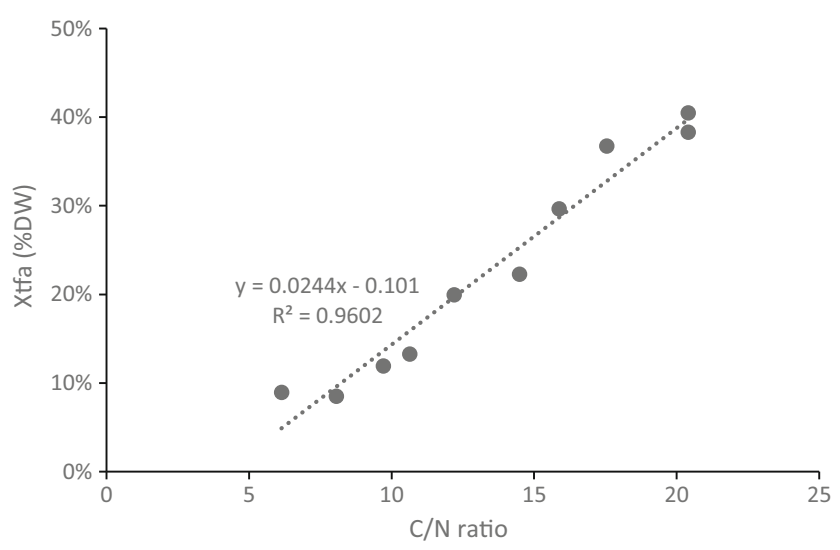

Fig. 9 Total fatty acid content in Chlorococcum littorale depicted against elemental $\mathrm{C} / \mathrm{N}$ ratio

routine measure because elemental analysis is not widely available. The good correlation between fatty acid content and $\mathrm{C} / \mathrm{N}$ ratio $\left(R^{2}=0.96\right)$ is an indication that both analyses carried out in the current work were precise.

Acknowledgments Mass spectroscopy was performed by Tvente University, the Netherlands.

Author contributions Niels-Henrik NorskerLaboratory and field work. Preparation of manuscript

Maria CuaresmaLaboratory work and data preparation, review of manuscript

Pauliina UronenOverall study planning, review of manuscript

Maria BarbosaReview of manuscript

René WijffelsProject coordination, review of manuscript

Funding Funding for the study was provided by Neste Corporation.

\section{Compliance with ethical standards}

Conflicts of interest Pauliina Uronen is an employee of Neste Corporation. The other authors declare no conflicts of interest

Open Access This article is licensed under a Creative Commons Attribution 4.0 International License, which permits use, sharing, adaptation, distribution and reproduction in any medium or format, as long as you give appropriate credit to the original author(s) and the source, provide a link to the Creative Commons licence, and indicate if changes were made. The images or other third party material in this article are included in the article's Creative Commons licence, unless indicated otherwise in a credit line to the material. If material is not included in the article's Creative Commons licence and your intended use is not permitted by statutory regulation or exceeds the permitted use, you will need to obtain permission directly from the copyright holder. To view a copy of this licence, visit http://creativecommons.org/licenses/by/4.0/.

\section{References}

Acién Fernández FG, Fernández Sevilla JM, Sánchez Pérez JA, Molina Grima E, Chisti Y (2001) Airlift-driven external-loop tubular photobioreactors for outdoor production of microalgae: assessment of design and performance. Chem Eng Sci 56: $2721-2732$

Ahmad FB, Zhang Z, Doherty WO, O'Hara IM (2018) Optimising extraction of microalgal oil using accelerated solvent extraction by response surface methodology. J Eng Sci Technol 13:964-976

Benvenuti G, Bosma R, Cuaresma M, Janssen M, Barbosa MJ, Wijffels RH (2015) Selecting microalgae with high lipid productivity and photosynthetic activity under nitrogen starvation. J Appl Phycol 27:1425-1431

Bono M, Garcia R, Sri-Jayantha D, Ahner B, Kirby B (2015) Measurement of lipid accumulation in Chlorella vulgaris via flow cytometry and liquid-state ${ }^{1} \mathrm{H}$ NMR spectroscopy for development of an NMR-traceable flow cytometry protocol. PLoS One 10: e0134846

Bosma R, Miazek K, Willemsen SM, Vermue MH, Wijffels RH (2008) Growth inhibition of Monodus subterraneus by free fatty acids. Biotechnol Bioeng 101:1108-1114

Breuer G, Lamers PP, Martens DE, Draaisma RB, Wijffels RH (2012) The impact of nitrogen starvation on the dynamics of triacylglycerol accumulation in nine microalgae strains. Bioresour Technol 124: $217-226$

Breuer G, Evers WA, de Vree JH, Kleinegris DM, Martens DE, Wijffels RH, Lamers PP (2013) Analysis of fatty acid content and composition in microalgae. J Vis Exp e50628

Cabanelas ITD, Zwart M, Kleinegris DMM, Wijffels RH, Barbosa MJ (2016) Sorting cells of the microalga Chlorococcum littorale with increased triacylglycerol productivity. Biotechnol Biofuels 9:183195

Cavonius LR, Carlsson N-G, Undeland I (2014) Quantification of total fatty acids in microalgae: comparison of extraction and transesterification methods. Anal Bioanal Chem 406:7313-7322

Choi KJ, Nakhost Z, Bárzana E, Karel M (1987) Lipid content and fatty acid composition of green algae Scenedesmus obliquus grown in a constant cell density apparatus. Food Biotechnol 1:117-128

Cointet E, Wielgosz-Collin G, Méléder V, Gonçalves O (2019) Lipids in benthic diatoms: a new suitable screening procedure. Algal Res 39: 101425

Giordano M, Wang Q (2018) Microalgae for industrial purposes. In: Vaz S Jr (ed) Biomass and Green Chemistry. Springer, Cham, pp 133167

Guerra LT, Levitan O, Frada MJ, Sun JS, Falkowski PG, Dismukes GC (2013) Regulatory branch points affecting protein and lipid biosynthesis in the diatom Phaeodactylum tricornutum. Biomass Bioenergy 59:306-315

Ho T-Y, Quigg A, Finkel ZV, Milligan AJ, Wyman K, Falkowski PG, Morel FMM (2003) The elemental composition of some marine phytoplankton. J Phycol 39:1145-1159

Klok AJ, Martens DE, Wijffels RH, Lamers PP (2013) Simultaneous growth and neutral lipid accumulation in microalgae. Bioresour Technol 134:233-243

Lee TH, Chang JS, Wang HY (2013) Current developments in highthroughput analysis for microalgae cellular contents. Biotechnol J 8:1301-1314

Münkel R, Schmid-Staiger U, Werner A, Hirth TJB (2013) Optimization of outdoor cultivation in flat panel airlift reactors for lipid production by Chlorella vulgaris. Bioengineering 110:2882-2893

Norsker N-H, Barbosa MJ, Vermuë MH, Wijffels RH (2011) Microalgal production - A close look at the economics. Biotechnol Adv 29:24 27

Pruvost J, Van Vooren G, Cogne G, Legrand J (2009) Investigation of biomass and lipids production with Neochloris oleoabundans in photobioreactor. Bioresour Technol 100:5988-5995

Remmers IM, Hidalgo-Ulloa A, Brandt B, Evers WA, Wijffels RH, Lamers PP (2017) Continuous versus batch production of lipids in 
the microalgae Acutodesmus obliquus. Bioresour Technol 244: 1384-1392

Rodolfi L, Zittelli GC, Bassi N, Padovani G, Biondi N, Bonini G, Tredici MR (2009) Microalgae for oil: strain selection, induction of lipid synthesis and outdoor mass cultivation in a low-cost photobioreactor. Biotechnol Bioeng 102:100-112

Sergejevová M, Malapascua JR, Kopecký J, Masojídek J (2015) Photobioreactors with internal illumination. In: Prokop A, Bajpai K, Zappi ME (eds) Algal Biorefineries. Springer, Cham, pp 213236

Slegers PM, Wijffels RH, van Straten G, van Boxtel AJB (2011) Design scenarios for flat panel photobioreactors. Appl Energy 88:3342-3353

Solovchenko A, Khozin-Goldberg I, Recht L, Boussiba S (2010) Stressinduced changes in optical properties, pigment and fatty acid content of Nannochloropsis sp.: implications for non-destructive assay of total fatty acids. Mar Biotechnol:1-9

Terry KL, Hirata J, Laws EA (1985) Light-limited, nitrogen-limited, and phosphorus-limited growth of Phaeodactylum tricornutum Bohlin strain TFX-1 - chemical-composition, carbon partitioning, and the diel periodicity of physiological processes. J Exp Mar Biol Ecol 86:85-100

Zou N, Richmond A (1999) Effect of light-path lengh in outdoor flat plate reactors on output rate of cell mass and on EPA in sp. J Biotechnol 70:351-356

Publisher's note Springer Nature remains neutral with regard to jurisdictional claims in published maps and institutional affiliations. 